\title{
Analisis dan Perancangan Sistem Informasi Inventory Barang pada PT Cipta Rasa Multindo
}

\author{
Nuryasin $^{1}$, Alvin Handrianto Saputra ${ }^{2}$, Tomi Hardi ${ }^{3}$, Irfan Fadholur ${ }^{4}$
}

\begin{abstract}
Abstrak-Cipta Rasa Multindo merupakan perusahaan manufaktur yang bergerak di bidang produksi pastry dan bakery. Sebagai perusahaan manufaktur pengelolaan inventory sangatlah penting untuk meningkatkan kinerja perusahaan dalam mengelola stok barang. Saat ini sistem inventory yang berjalan masih manual dan memiliki banyak kelemahan dan kekurangan sehingga menyebabkan kinerja perusahaan menjadi terhambat dan belum mampu menunjang segala kebutuhan yang diinginkan perusahaan seperti proses mulai dari pencatatan barang hingga perekapan laporan yang cukup memakan waktu. Penelitian ini bertujuan untuk menganalisis dan merancang suatu sistem informasi inventory barang yang dibutuhkan oleh perusahaan. Metode analisis Performance, Information, Economy, Control, Eficiency, dan Service (PIECES) digunakan untuk membantu proses analisis sistem yang berjalan. Merancang dan mendesain sistem informasi inventory barang menggunakan metode Rapid Application Development (RAD) sebagai metode pengembangan sistem dan Unified Modelling Language (UML) sebagai alat pemodelannya. Dengan dikembangkannya analisis dan perancangan sistem ini mampu meningkatkan kinerja perusahaan menjadi lebih efektif dan efisien.
\end{abstract}

Kata kunci-Analisis PIECES, Inventory, Rapid Application Development (RAD), Sistem Informasi, Unified Modelling Language (UML).

\section{Pendahuluan}

$\mathrm{S}$ eiring berkembanganya kemajuan teknologi informasi menjadikan persaingan bisnis dalam dunia usaha semakin ketat. Jumlah perusahaan semakin banyak dan semakin berusaha untuk mempertahankan bisnisnya dengan menerapkan strategi baru. Dengan semakin ketatnya persaingan bisnis dalam dunia usaha, kecepatan dan ketepatan dalam bertindak merupakan suatu hal yang utama. Pengelolaan informasi yang baik pada suatu perusahaan sangat diperlukan untuk meningkatkan kinerja perusahaan [1].

Received: 12 Februari 2019; Revised: 15 Maret 2019; Accepted: 1 April 2019 Nuryasin, Prodi Sistem Informasi, UIN Syarif Hidayatullah Jakarta, Indonesia (email: nuryasin@uinjkt.ac.id)

A. H. Saputra, PT. Cipta Rasa Multindo Jakarta, Indonesia (email: alvinhandriantos19@gmail.com)

T. Hardi, Teknik Informatika, Universitas Pamulang, Tangerang Selatan, Indonesia (e-mail: tomi.hardi@unpam.ac.id)

I. F. Rahman, Cybertrend Data Academy Jakarta, Indonesia (email: irfan.rahman@dataacademy.co.id)

http://journal.uinjkt.ac.id/index.php/aism
PT Cipta Rasa Multindo merupakan perusahaan manufaktur yang bergerak pada bidang makanan yang memproduksi bermacam-macam jenis roti dan kue yang bergerak di bawah nama Maison Pierre. Sebagai perusahaan manufaktur inventory merupakan simpanan bahan baku dan barang setengah jadi (work in proses) untuk diproses menjadi barang jadi (finished goods) yang mempunyai nilai tambah lebih besar secara ekonomis, untuk selanjutnya dijual kepada pihak ketiga (konsumen) [2]. Inventory barang pada perusahaan sangat penting karena dari inventory tersebut perusahaan dapat mengelola stok barang dan memonitor barang masuk dan barang keluar agar suatu perusahaan tidak mengalami kelebihan atau kekurangan barang yang akan berdampak buruk pada perusahaan [3].

Pengelolaan inventory pada PT Cipta Rasa Multindo saat ini masih manual. PT Cipta Rasa Multindo dalam melakukan pengecekan stok setiap hari dengan mengecek semua stok dalam gudang dan pencatatan barang masuk maupun keluar masih menggunakan buku yang akan diisi dengan jumlah persediaan barang yang masuk dan keluar kemudian diarsipkan dan dipindahkan ke Microsoft Excel untuk disimpan dan sebagai acuan untuk kemudian diolah menjadi informasi. Proses tersebut dinilai memakan waktu dan kurang efisien sehingga sering kali terjadi kesalahan dalam pencatatan, data yang kurang akurat, kekurangan dan kelebihan stok, dan menyebabkan terlambatnya proses produksi. Keterlambatan tersebut mengakibatkan konsumen mengalami kekecewaan dan memungkinkan konsumen untuk berpindah ke perusahaan lain karena sudah tidak percaya lagi dengan kinerja PT Cipta Rasa Multindo yang berujung menjadi kerugian karena hilangnya pelanggan.

Berdasarkan uraian permasalahan diatas peneliti tertarik untuk melakukan penelitian terkait pembangunan sebuah sistem informasi inventory di PT Cipta Rasa Multindo dengan judul "Analisis dan Perancangan Sistem Informasi Inventory Barang Pada PT. Cipta Rasa Multindo". Hasil dari penelitian ini diharapkan menjadi solusi terbaik untuk pengelolaan inventory barang pada PT Cipta Rasa Multindo yang akan lebih baik dan meminimalisir terjadinya kesalahan yang sering terjadi. 


\section{A. Tujuan Penelitian}

Adapun tujuan penelitian ini adalah sebagai berikut:

1) Menganalisis dan merancang sistem informasi inventory barang yang dapat menunjang aktivitas penyimpanan, pengelolaan barang, dan pengurangan penggunaan kertas pada PT Cipta Rasa Multindo.

2) Mempermudah proses pencatatan dan pengelolaan stok barang dengan menawarkan sistem baru.

3) Merancang sistem yang dapat menyajikan informasi persediaan barang dan laporan yang akurat dan cepat sesuai kebutuhan perusahaan.

4) Meminimalisir kelebihan dan kekurangan stok barang dengan adanya sistem baru yang membantu mengolah data sehingga menghasilkan informasi yang akurat dan cepat.

\section{B. Ruang Lingkup}

Agar penelitian yang dilakukan lebih terarah dan terstruktur maka penulis membuat ruang lingkup sebagai berikut:

1) Ruang lingkup pembahasan meliputi proses pencatatan barang masuk dan keluar, pengelolaan data permintaan dan persediaan barang, dan pembuatan laporan.

2) Menggunakan metode pengembangan sistem Rapid Application Development (RAD) dan menggunakan Unified Modelling Language (UML) versi 2.5.1 sebagai alat pemodelannya.

Menggunakan metode analisis PIECES (Performance, Information, Economy, Control, Eficiency, dan Service) untuk membantu dalam proses analisis.

\section{KAJIAN PENELITIAN}

Sistem informasi adalah suatu sistem di dalam suatu organisasi yang mempertemukan kebutuhan pengolahan transaksi harian yang mendukung fungsi operasi organisasi yang bersifat manajerial dengan kegiatan strategi dari suatu organisasi untuk dapat menyediakan laporan-laporan yang diperlukan oleh pihak luar tertentu [4-6].

Analisis PIECES adalah metode analisis sebagai dasar untuk memperoleh pokok-pokok permasalahan yang lebih spesifik [7-9]. Dalam menganalisis sebuah sistem, biasanya akan dilakukan terhadap beberapa aspek antara lain adalah kinerja, informasi, ekonomi, keamanan aplikasi, efisiensi dan pelayanan pelanggan. Analisis PIECES ini sangat penting untuk dilakukan karena dalam analisis ini biasanya akan ditemukan beberapa masalah utama maupun masalah yang bersifat gejala dari masalah utama [10-12].

Inventory (persediaan) merupakan bahan atau barang yang disimpan untuk tujuan tertentu, antara lain untuk proses produksi, jika berupa bahan mentah maka akan diproses lebih lanjut, jika berupa komponen (spare part) maka akan dijual kembali menjadi barang dagangan [13-16]. Inventory (persediaan) dapat juga berarti stok dari suatu item atau sumber daya yang digunakan dalam suatu organisasi perusahaan [17].

Rapid Application Development (RAD) adalah suatu pendekatan berorientasi objek terhadap pengembangan sistem yang mencakup suatu metode pengembangan serta perangkat-perangkat lunak $[18,19]$. RAD bertujuan mempersingkat waktu yang biasanya diperlukan dalam siklus hidup pengembangan sistem tradisional antara perancangan dan penerapan suatu sistem informasi [20].

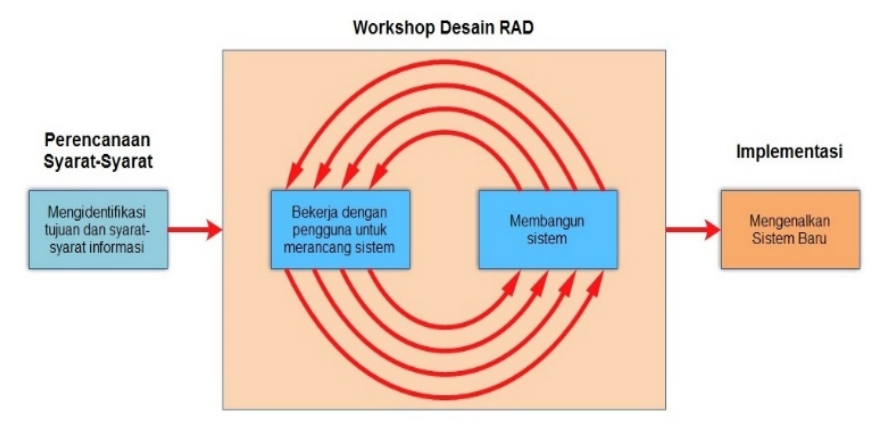

Gambar 1. Siklus Rapid Application Development

Unified Modeling Language (UML) adalah bahasa grafis yang kompleks dan kaya dengan fitur [21]. UML adalah sebuah bahasa yang telah menjadi standar dalam industri untuk visualisasi, merancang, dan mendokumentasikan sistem peranti lunak [22-25]. UML yang digunakan pada penelitian ini antara lain sebagai berikut:

1) Use case diagram

2) Activity diagram

3) Class diagram

4) Squence diagram

\section{Metode Penelitian}

\section{A. Metode Pengumpulan Data}

Metode pengumpulan data dimaksudkan oleh peneliti untuk mendapatkan data dan informasi yang diperlukan untuk mendapatkan kebenaran materi uraian pembahasan, dan untuk mendapatkan data yang berkaitan dengan kondisi organisasi pada masa sekarang yang kemudian akan diolah untuk membuat perancangan sistem yang akan diusulkan. Metode pengumpulan data yang dilakukan pada penelitian ini adalah sebagai berikut:

1) Observasi

2) Wawancara

3) Studi Pustaka

4) Studi Lierautr Sejenis

\section{B. Metode Pengembangan Sistem}

Dalam pembuatan RAD dalam studi kasus ini terdapat beberapa tahap pengembangan yaitu tahap requirement planning dan workshop design.

\section{1) Tahap Requirement Planning}

Pada tahap ini dilakukan analisis permasalahan terhadap sistem yang sedang berjalan dengan bantuan metode analisis 
PIECES. Selanjutnya dilakukan analisis kebutuhan sistem untuk menerangkan apa saja yang dibutuhkan untuk membangun sistem inventory di PT. Cipta Rasa Multindo.

\section{2) Tahap Workshop Design}

Tahap workshop design terbagi menjadi tiga bagian yaitu desain proses, desain database, dan desain interface. Dalam desain proses terdiri dari use case diagram dan activity diagram sedangkan dalam desain database terdeiri dari class diagram, mapping cardinality, dan sequence diagram.

\section{HASIL}

PT Cipta Rasa Multindo memulai bisnisnya dengan memasok produknya ke seluruh Jakarta dan kemudian menyebar ke berbagai daerah seperti Tangerang dan sekitarnya. Saat ini perusahaan PT Cipta Rasa Multindo memiliki tempat seluas $800 \mathrm{~m}^{2}$ dengan sertifikat HACCP (Hazard Analysis and Critical Control Points) dan sertifikat halal. PT Cipta Rasa Multindo setiap bulannya memproduksi produk campuran sekitar 300.000 buah produk dan masih dapat ditingkatkan. Saat ini PT Cipta Rasa Multindo memproduksi lebih dari 200 jenis produk roti dan kue.

Berikut adalah hasil dari analisis permasalahan menggunakan PIECES yang disajikan dalam bentuk tabel (Tabel 1).

Tabel 1.

Analisis PIECES

\begin{tabular}{|c|c|}
\hline Analisis & Sistem Berjalan \\
\hline $\begin{array}{l}\text { Performance } \\
\text { (Performa/ Kinerja) }\end{array}$ & $\begin{array}{l}\text { Bertambahnya permintaan pelanggan membuat } \\
\text { aktifitas pada bagian gudang meningkat sehingga } \\
\text { proses pencatatan data dan pembuatan laporan } \\
\text { yang masih manual memakan cukup banyak waktu } \\
\text { dan mengakibatkan turunnya performa atau kinerja } \\
\text { perusahaan. }\end{array}$ \\
\hline $\begin{array}{l}\text { Information } \\
\text { (Informasi) }\end{array}$ & $\begin{array}{l}\text { Cukup sering terjadi kesalahan pada saat } \\
\text { pencatatan data ke dalam buku catatan seperti salah } \\
\text { penulisan dan tulisan yang kurang dapat dibaca } \\
\text { sehingga terjadi kesalahan saat pemindahan data ke } \\
\text { dalam Microsoft Excel yang berakibat kepada } \\
\text { salahnya informasi yang dihasilkan. }\end{array}$ \\
\hline Economy (Ekonomi) & $\begin{array}{l}\text { Pemakaian kertas yang berlebih membuat } \\
\text { perusahaan mengeluarkan biaya lebih untuk } \\
\text { pembelian kertas serta alat tulisnya. }\end{array}$ \\
\hline Control (Kontrol) & $\begin{array}{l}\text { Tidak adanya } \log \text { history karena dalam pencatatan } \\
\text { data ke dalam buku catatan tidak diketahui staf } \\
\text { gudang yang mana yang mencatatnya sehingga } \\
\text { rentan terjadinya penyalahgunaan atau eksploitasi } \\
\text { pada sistem. }\end{array}$ \\
\hline Efficiency (Efisiensi) & $\begin{array}{l}\text { Proses-proses yang dilakukan dengan adanya } \\
\text { sistem lama memakan cukup banyak waktu dan } \\
\text { biaya sehingga dinilai kurang efisien dan kurang } \\
\text { efektif. }\end{array}$ \\
\hline Service (Layanan) & $\begin{array}{l}\text { Kurangnya layanan yang diberikan oleh sistem } \\
\text { lama membuat pengguna kesulitan dalam } \\
\text { melakukan aktifitas pada bagian gudang. }\end{array}$ \\
\hline
\end{tabular}

Berdasarkan permasalahan yang ada penulis melakukan analisis dan memberikan solusi berupa sistem usulan yang nantinya akan digunakan oleh perusahaan. Berikut ini adalah sistem yang akan diusulkan (Gambar 2):

http://journal.uinjkt.ac.id/index.php/aism

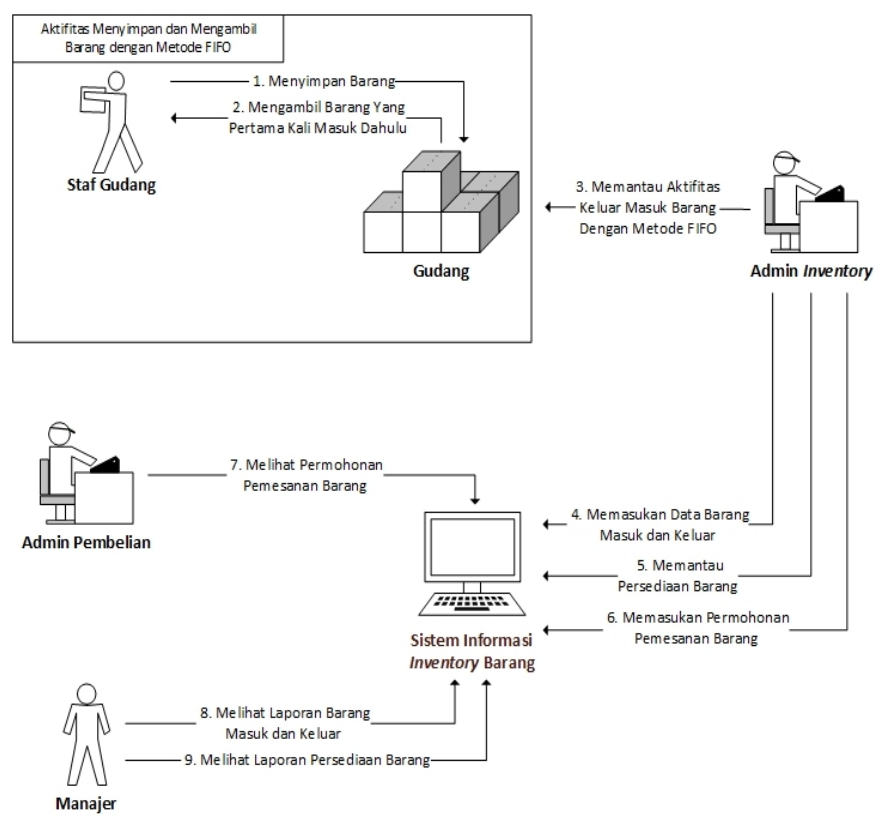

Gambar 2. Sistem Usulan

Pada tahap ini akan dijelaskan proses perancangan sistem yang diusulkan dimulai dari pembuatan use case diagram kemudian activity diagram sebagai desain proses dari sebuah sistem informasi inventory barang pada penelitian ini.

\section{A. Use case diagram}

Berikut merupakan use case diagram yang dirancang untuk sistem informasi inventory barang pada PT Cipta Rasa Multindo:

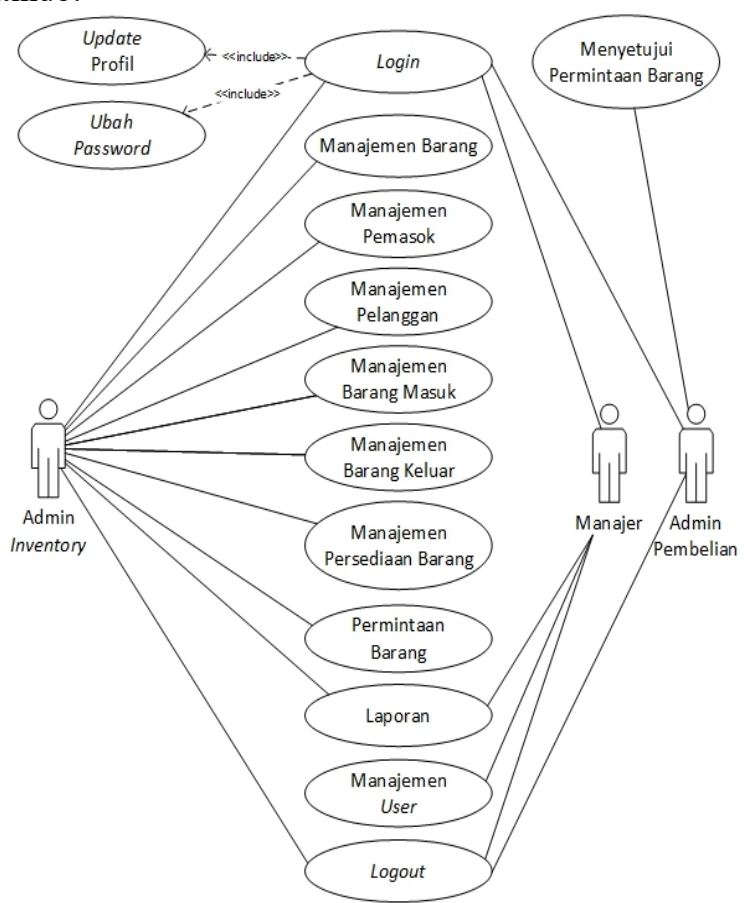

Gambar 3. Use Case Diagram Sistem Informasi Inventory Barang 
B. Activity diagram:

Berdasarkan use case yang telah ditetapkan sebelumnya, dilakukan pemodelan aktivitas pada sistem dan berikut adalah beberapa contoh activity diagram yang dirancang:

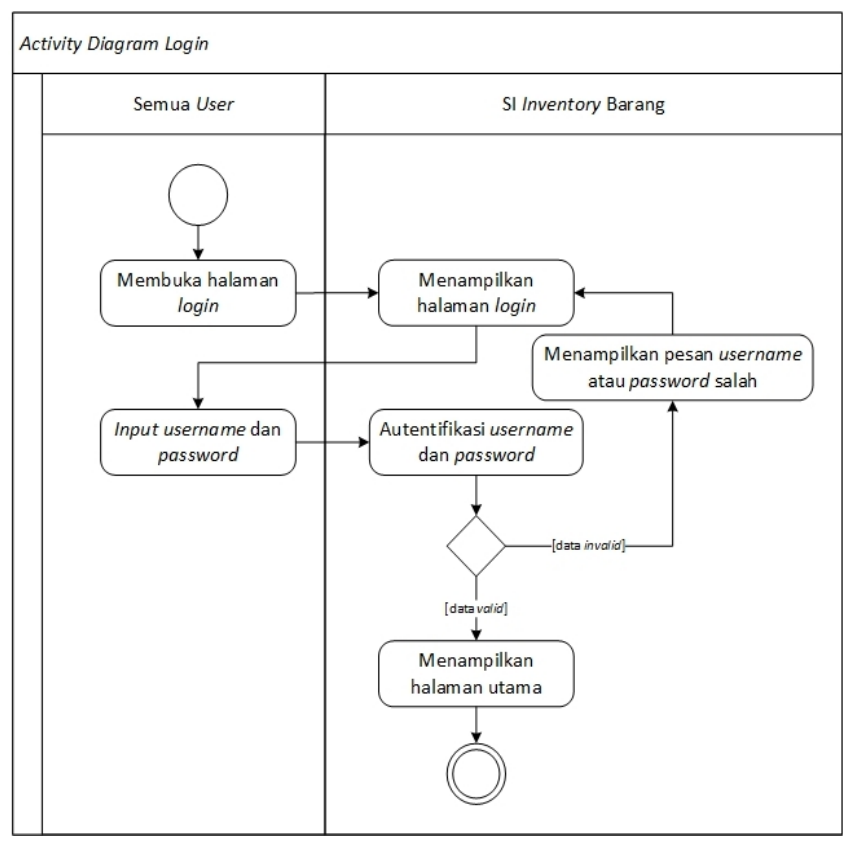

Gambar 4. Activity Diagram Login

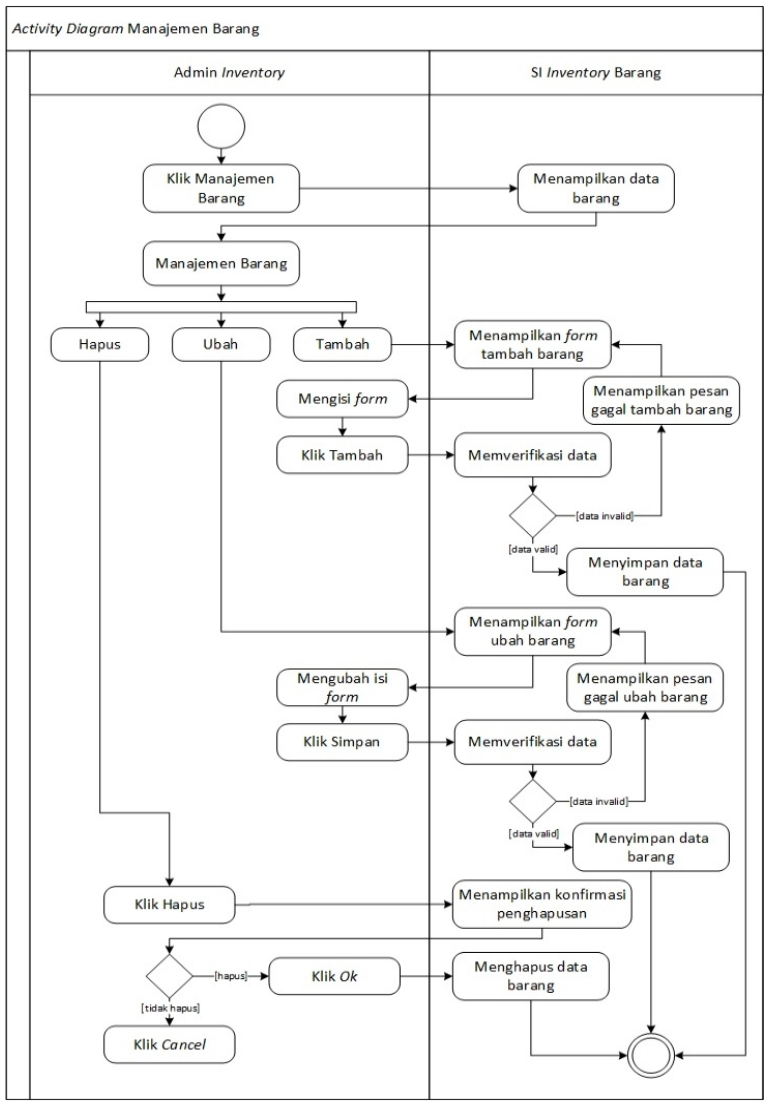

Gambar 5. Activity Diagram Manajemen Barang

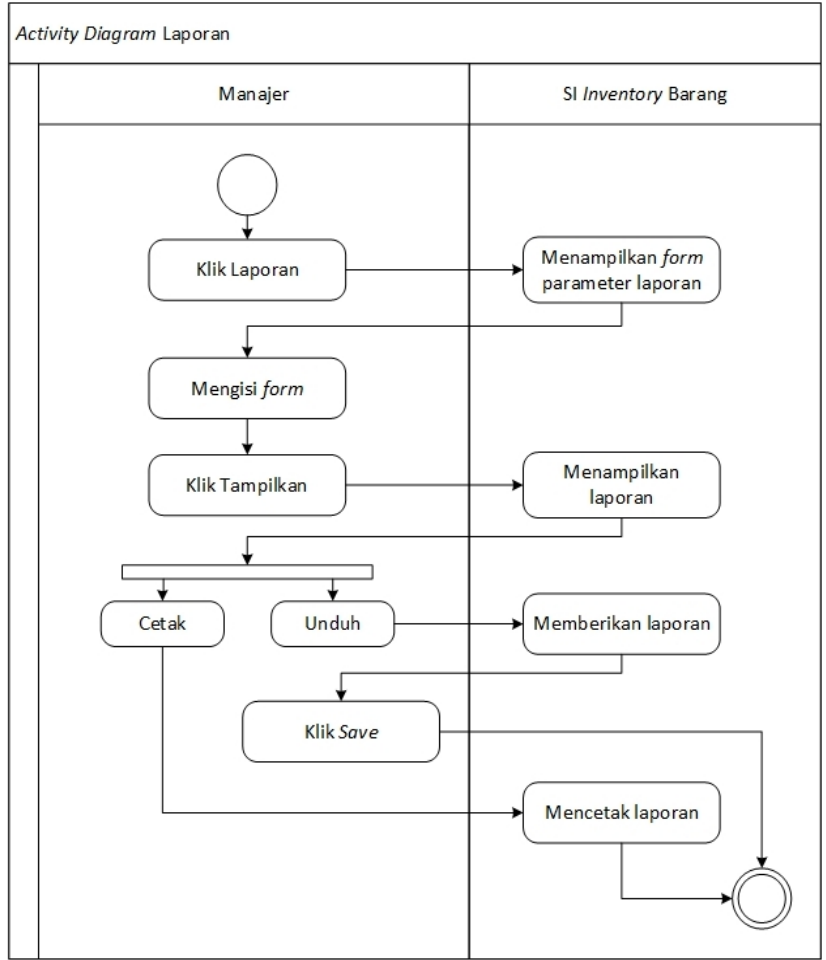

Gambar 6. Activity Diagram Laporan

C. Class diagram:

Tahapan pertama dalam mendesain database pada penelitian ini adalah membuat class diagram.

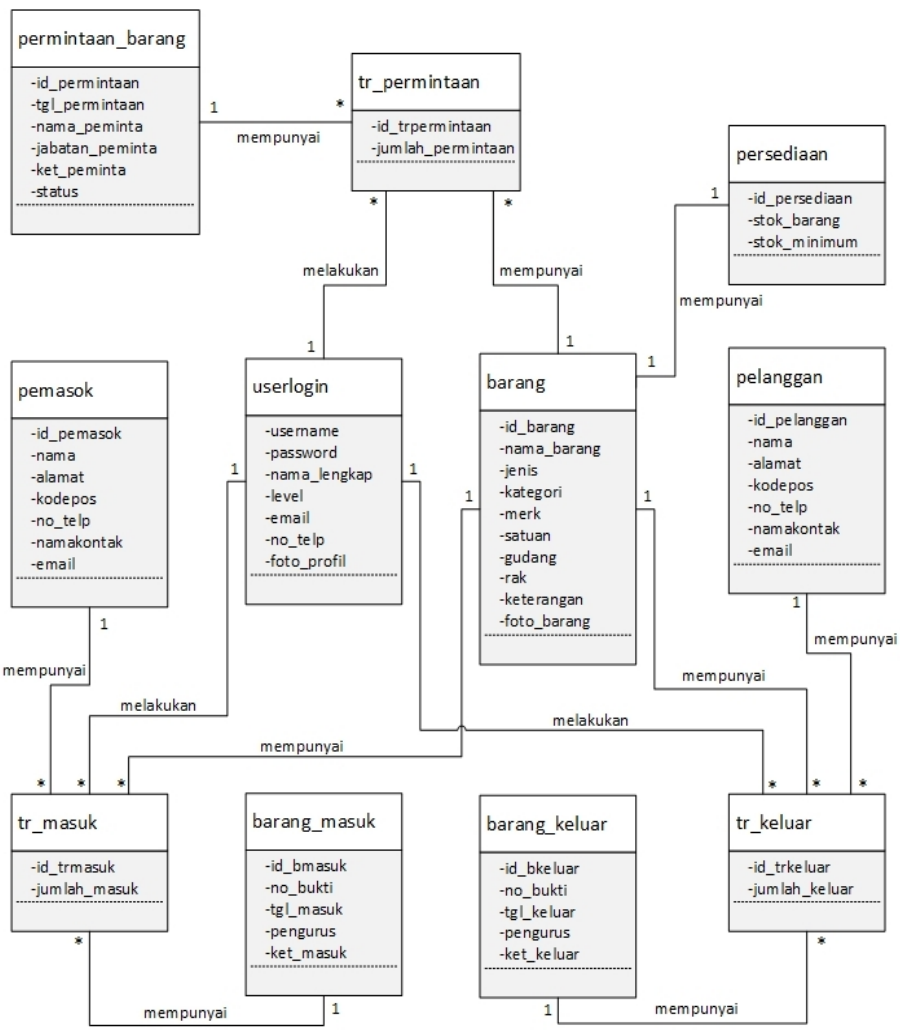

Gambar 7. Class Diagram 


\section{Mapping cardinality:}

Setelah membuat class diagram tahapan selanjutnya adalah membuat mapping cardinality dimana akan ada penjelasan mengenai primary key dan foreign key dalam setiap tabelnya.

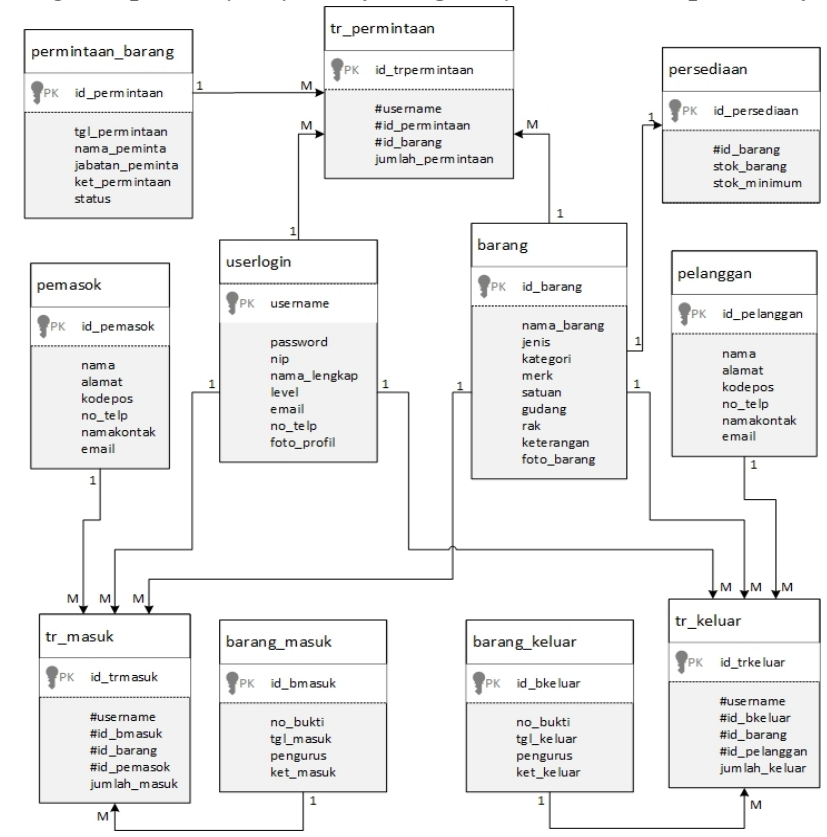

Gambar 8. Mapping Cardinality

\section{E. Sequence diagram:}

Tahap selanjutnya merupakan perancangan sequence diagram untuk memodelkan interaksi objek di dalam sebuah usecase (proses) dan berikut adalah beberapa contoh sequence diagram yang dirancang, ilustrasi Sequence diagram terdapat pada Gambar 9 dan 10:

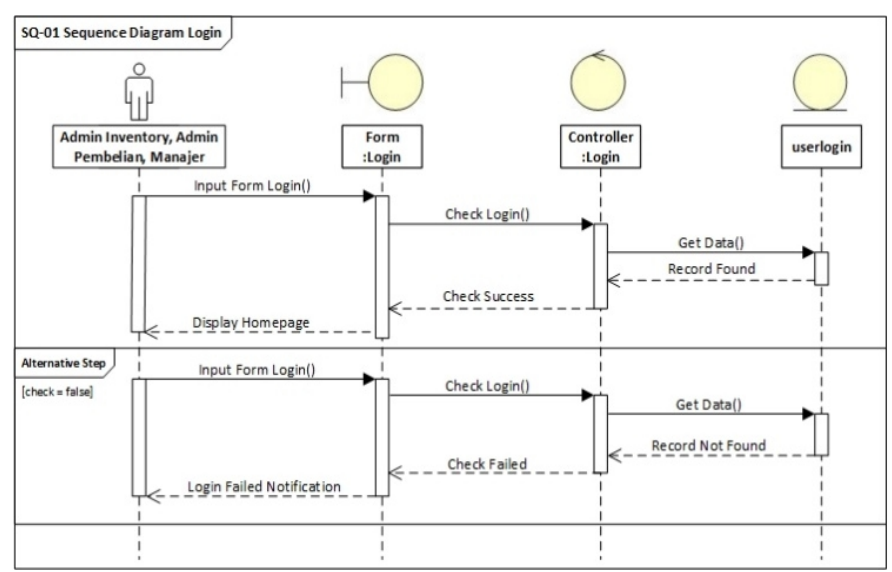

Gambar 9. Sequence Diagram Login

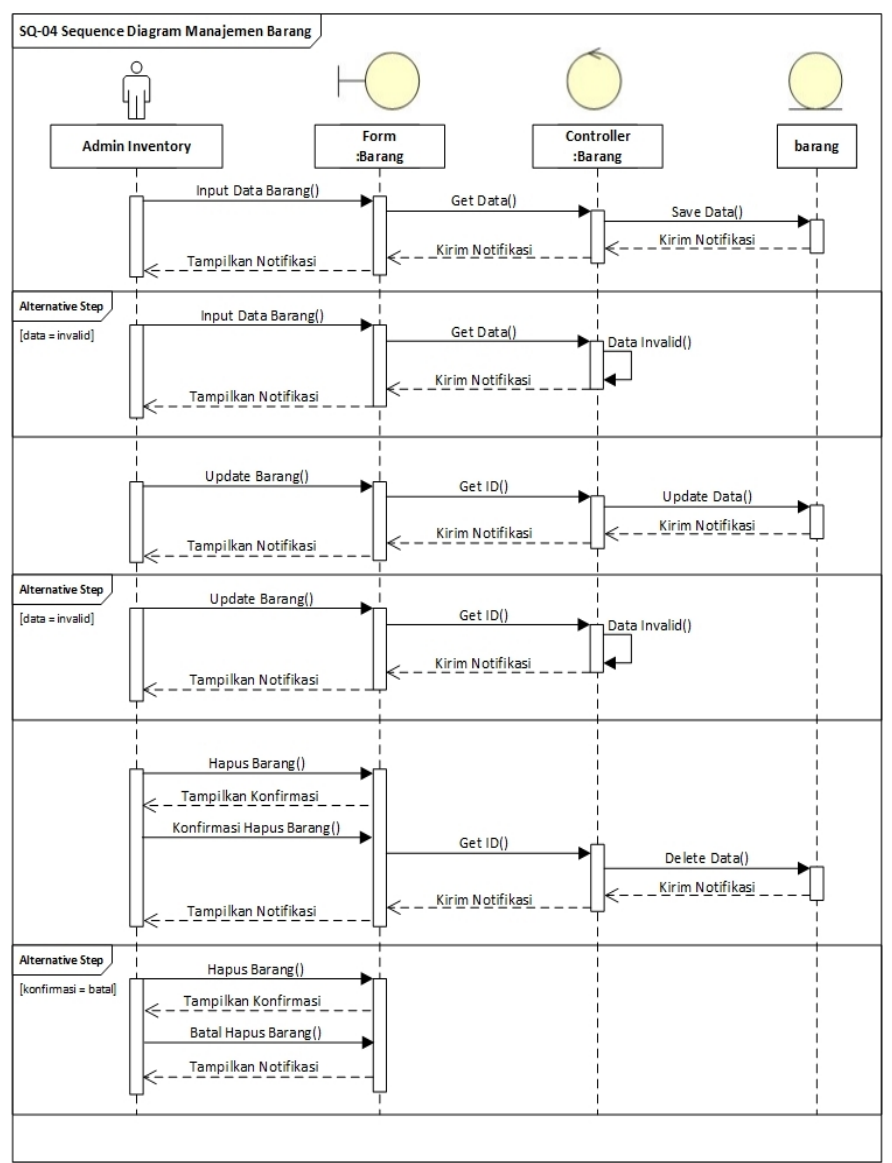

Gambar 10. Sequence Diagram Manajemen Barang

Tahapan selanjutnya adalah mendesain tampilan antarmuka yang nantinya akan dibuat sebagai acuan dalam membangun website Sistem Informasi Inventory Barang dan berikut beberapa contoh desain tampilan yang dibuat: 


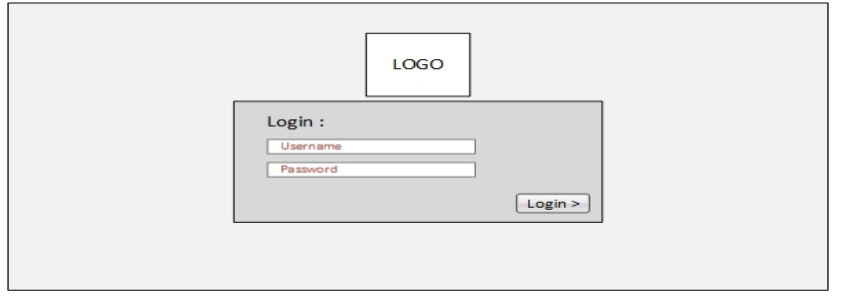

Gambar 11. Desain Tampilan Login

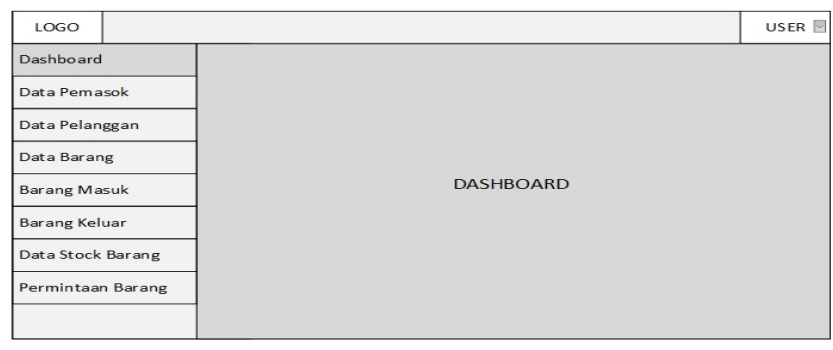

Gambar 12. Desain Tampilan Dashboard

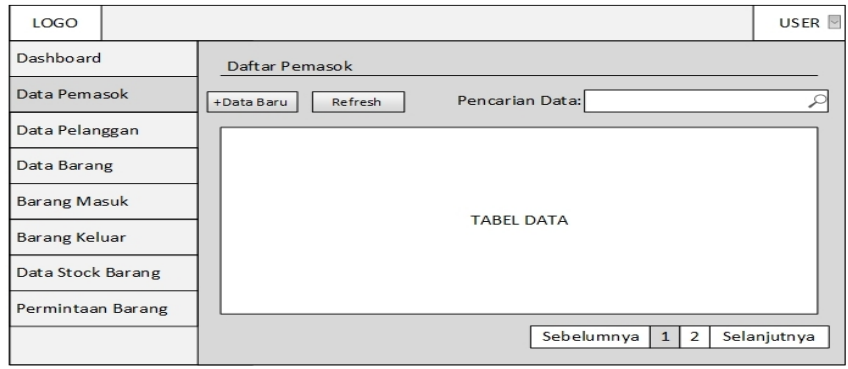

Gambar 13. Desain Tampilan Data Pemasok

\section{KeSIMPULAN}

Usulan rancangan sistem informasi inventory barang diharapkan dapat membantu memudahkan PT Cipta Rasa Mutindo dalam pengolahan data barang sehingga menjadi lebih efektif dan efisien serta menyelesaikan masalah yang ada pada sistem lama. Usulan rancangan sistem informasi inventory barang diharapkan dapat menyelesaikan masalah kekurangan dan kelebihan stok yang ada pada PT Cipta Rasa Multindo. Sistem informasi inventory barang dirancang menggunakan metode Rapid Application Development (RAD) dan Unified Modelling Language (UML) untuk pemodelannya.

Untuk pengembangan dari penelitian ini agar menjadi penelitian yang lebih baik maka peneliti memberikan saran untuk mengimplementasikan usulan rancangan sistem informasi inventory barang pada PT Cipta Rasa Multindo dan pengembangan rancangan sistem informasi inventory barang ini dapat dikembangkan ke bagian pembelian dan penjualan barang.

\section{REFERENCES}

[1] O. Palevi, A. Mulyani, dan M. Khoir, "Sistem Informasi Inventori Barang Menggunakan Metode Object Oriented Di Pt," PROSISKO: Jurnal Pengembangan Riset dan Observasi Sistem Komputervol. 5, no. 1, pp. 27-35, 2018.

[2] A. Prawirosentono, Jakarta, "Riset Operasi dan Ekonofisika," 2005.

[3] Basten, et al., "System-oriented inventory models for spare parts," Surveys in operations research management science Journal, vol. 19, no. 1, pp. 34-55, 2014.

[4] D. Purnomo, "Model Prototyping Pada Pengembangan Sistem Informasi," JIMP-Jurnal Informatika Merdeka Pasuruan, vol. 2, no. 2, pp. 54-61, 2017.

[5] A. Rusdiana, M. Irfan, and M. Irfan, "Sistem informasi manajemen," ed: Pustaka Setia, 2014.

[6] M. B. Romney and P. J. Steinbart, "Sistem informasi akuntansi," 2016.

[7] I. D. Mumpuni, W. A. Dewa, "Analisis dan Pengembangan Sistem Self Services Terminal (SST) dengan Pendekatan PIECES pada STMIK Pradnya Paramita Malang," Jurnal MATICS, vol. 9, no. 1, pp. 12-17, 2017.

[8] A. Supriyatna, V. Maria, "Analisa tingkat kepuasan pengguna dan tingkat kepentingan penerapan sistem informasi djp online dengan kerangka pieces," Khazanah Informatika: Jurnal Ilmu Komputer Dan Informatika, vol. 3, no. 2, pp. 88-94, 2017.

[9] W. Ragil, "Pedoman sosialisasi prosedur operasi standar," 2010.

[10] F. Dzulfikar, Nurzam, "Studi Kelayakan Bisnis dan Analisis SWOT PIECES (Studi Kasus: E-Commerce Broker Mobil Yogyakarta),"Semnasteknomedia online, vol. 4, no. 1, pp. 2-10-1, 2016.

[11] N. Alfie, Rahmi, "Analisis Pieces Sistem Tracer Study Online Berbasis Website Di Universitas AMIKOM Yogyakarta," Jurnal Data Manajemen dan Teknologi Informasi, vol. 18, no. 2, pp. 37-41, 2017.

[12] A. Setyaningrum, "Analisis Sistem Informasi Registrasi Pasien Dengan Metode Pieces Di Rumah Sakit Mulia Hati Wonogiri," Universitas Muhammadiyah Surakarta, 2015.

[13] M. Minarni, Susanti, "Sistem Informasi Inventory Obat Pada Rumah Sakit Umum Daerah (RSUD) Padang," Jurnal Momentum ISSN -752X, vol. 16, no. 1, pp. 103-111, 2014.

[14] J. Junaidi, et al., "Rancang Bangun Aplikasi Sistem Inventory Berbasis Desktop Menggunakan JSE," 2015.

[15] M. O. Veza, M. Ropianto, "Perancangan Sistem Informasi Inventory Data Barang Pada PT. Andalas Berlian Motors," Jurnal Teknik Ibnu Sina, vol. 2, no. 2, pp. 121-134, 2017.

[16] S. Bradshaw, Howard, "Challenging truth and trust: A global inventory of organized social media manipulation," vol. 1, 2018.

[17] S. Assauri, "Manajemen operasi produksi," 2016.

[18] S. Kosasi, Yuliani, D. A. Eka, "Penerapan Rapid Application Development Pada Sistem Penjualan Sepeda Online," Simetris: Jurnal Teknik Mesin, Elektro dan Ilmu Komputer, vol. 6, no. 1, pp. 27-36, 2015.

[19] R. Delima, et al., "Development of Dutatani Website Using Rapid Application Development," Jurnal IJITEE, vol. 1, no. 2, pp. 36-44, 2017.

[20] B. P. Kumar and Y. Prashanth, "Improving the rapid application development process model," in 2014 Conference on IT in Business, Industry and Government (CSIBIG), 2014, pp. 1-3: IEEE.

[21] Y. Sugiarti, "Dasar-Dasar pemrograman Java Netbeans Database, UML, dan Interface," 2018.

[22] K. Nugroho, "Perancangan Aplikasi Mobile Berbasis SMS Gateway dan Web Engineering dengan Unified Modelling Language (UML)," 2017.

[23] N. A. Musthofa, S. Mutrofin, M. A. Murtadho, "Implementasi Quick Response (Qr) Code Pada Aplikasi Validasi Dokumen Menggunakan Perancangan Unified Modelling Language (Uml)," ANTIVIRUS: Jurnal Ilmiah Teknik Informatika, vol. 10, no. 1, pp. 42-50 2016.

[24] M. Read, et al., "Modelling biological behaviours with the unified modelling language: an immunological case study and critique," Journal of the Royal Society Interface, vol. 11, no. 99, pp. 1-16, 2014.

[25] A. Hidayat, V. G. Utomo, "Adaptive Online Module Prototype for Learning Unified Modelling Language (UML)," International Journal of Electrical Computer Engineering, vol. 6, no. 6, pp. 2931-2938, 2016. 